\title{
PEMODELAN RATA-RATA LAMA SEKOLAH MENGGUNAKAN PENDEKATAN REGRESI NONPARAMETRIK SPLINE MULTIVARIABLE
}

\author{
Ni Luh Gede Sinta Aryati ${ }^{\S}$, I Komang Gde Sukarsa ${ }^{2}$, I Gusti Ayu Made Srinadi ${ }^{3}$
}

\author{
${ }^{1}$ Program Studi Matematika, Fakultas MIPA - Universitas Udayana [Email : sintaaryati@gmail.com] \\ ${ }^{2}$ Program Studi Matematika, Fakultas MIPA - Universitas Udayana [Email : gedesukarsa@unud.ac.id] \\ ${ }^{3}$ Program Studi Matematika, Fakultas MIPA - Universitas Udayana [Email : srinadi@ unud.ac.id] \\ ${ }^{\S}$ Corresponding Author
}

\begin{abstract}
Mean years school (MYS) is one of the indicators used in calculating the human development index (HDI). The value of MYS Indonesia in 2019 is 8,75 which is still low. Therefore it still needs to be improved. In this research, MYS modeling will be carried out using six factors that are thought to influence MYS. This research uses multivariable spline nonparametric regression to modeling MYS Indonesia in 2019. The best model is selected based on the minimum value of Generalized Cross Validation (GCV). Based on this research, the best model obtained is a linear orde (orde 2) spline model with four knots. The model has $R^{2}$ value of $99,91 \%$.
\end{abstract}

Keywords: Mean Years School (MYS), Nonparametric, Spline, Knot, GCV.

\section{PENDAHULUAN}

Perkembangan ilmu pengetahuan dan teknologi mengakibatkan persaingan antarnegara menjadi semakin ketat. Pendidikan merupakan salah satu indikator yang perlu diperhatikan untuk meningkatkan kualitas sumber daya manusia agar dapat bersaing di era revolusi 4.0 ini. Kualitas sumber daya manusia dapat dilihat melalui indeks pembangunan manusia (IPM). Salah satu indikator IPM dalam bidang pendidikan yaitu rata-rata lama sekolah (RLS). RLS menunjukkan banyak tahun yang telah diselesaikan untuk menempuh pendidikan formal (BPS, 2020). Semakin besar RLS maka semakin banyak masyarakat yang dapat menyelesaikan pendidikan di tingkat yang lebih tinggi sehingga diharapkan dapat meningkatkan kualitas pendidikan masyarakat. Pada penelitian ini dilakukan pemodelan RLS masing-masing provinsi di Indonesia pada tahun 2019 menggunakan beberapa faktor yang diduga berpengaruh terhadap RLS. Terdapat enam faktor yang diduga dapat berpengaruh terhadap RLS yaitu persentase penduduk miskin, proporsi disabilitas anak, angka melek huruf, angka putus sekolah jenjang SD, angka putus sekolah jenjang SMP dan angka putus sekolah jenjang SMA.
Adapun metode statistika yang digunakan adalah regresi. Analisis regresi dapat berupa regresi parametrik, semiparametrik atau nonparametrik. Regresi parametrik mensyaratkan adanya asumsi mengenai bentuk kurva regresi. Akan tetapi terkadang bentuk kurva regresi sulit untuk diasumsikan. Oleh karena itu akan lebih baik jika menggunakan analisis regresi nonparametrik karena tidak mensyaratkan asumsi terhadap bentuk kurva regresi. Salah satu regresi nonparametrik yaitu regresi nonparametrik spline. Spline memberikan fleksibilitas yang lebih baik terhadap karakteristik suatu fungsi dengan membiarkan data mencari bentuk fungsi hubungannya sendiri. Selain itu spline juga mampu menjelaskan pola perilaku fungsi dalam sub-interval tertentu dan dapat digunakan untuk mengatasi atau mengurangi pola data yang mengalami peningkatan tajam dengan bantuan titik knot (Griggs, 2013). Spline bergantung pada penentuan titik knot optimal menggunakan nilai generalized cross validation (GCV) yang paling kecil.

Penelitian terdahulu yang menggunakan analisis regresi nonparametrik spline dilakukan oleh Prahutama et al. (2014) yang memodelkan nilai inflasi berdasarkan harga-harga pangan 
menggunakan spline multivariable, didapat model dengan nilai keofisien determinasi $\left(R^{2}\right)$ tertinggi yaitu sebesar 0,9394 pada orde 2 dengan 1 titik knot. Penelitian lainnya dilakukan oleh Astiti et al. (2016) yang memodelkan kemiskinan di Indonesia menggunakan analisis spline multivariable. Kesimpulan yang diperoleh dari penelitian tersebut adalah model terbaik model regresi spline kubik dengan lima titik knot dan nilai $R^{2}$ sebesar 0,9999. Beberapa penelitian tersebut menunjukkan bahwa regresi nonparametrik spline multivariable memberikan model yang baik dan dengan koefisien determinasi yang mendekati 1. Adapun tujuan dari penelitian ini yaitu mengetahui model yang tepat untuk memodelkan rata-rata lama sekolah di Indonesia menggunakan pendekatan regresi nonparametrik spline multivariable.

Regresi secara umum dapat dituliskan sebagai berikut (Kurtner \& Nachtsheim, 2004) :

$$
Y_{i}=f\left(X_{i}\right)+\varepsilon_{i} \quad ; i=1,2,3, \ldots, n
$$

dimana $Y_{i}$ adalah nilai variabel respons dalam amatan ke- $i, X_{i}$ adalah peubah bebas atau variabel prediktor dalam amatan ke- $i, f\left(X_{i}\right)$ adalah regresi yang telah diketahui bentuknya, $\varepsilon_{i}$ adalah suku galat atau sisaan yang diasumsikan independen dan bersifat acak dengan nilai tengah nol dan variansi $\sigma^{2}$ dalam amatan ke- $i$ dan $n$ adalah banyaknya amatan.

Regresi nonparametrik dapat dirumuskan sebagai berikut (Eubank, 1999) :

$$
y_{i}=f\left(t_{i}\right)+\varepsilon_{i} ; i=1,2, \ldots, n
$$

dengan $y_{i}$ adalah variabel respons dalam amatan ke-i, $f\left(t_{i}\right)$ adalah fungsi kurva regresi yang tidak diketahui bentuknya, $t_{i}$ adalah variabel prediktor, $\varepsilon_{i}$ adalah galat yang diasumsikan berdistribusi $\mathrm{N}\left(0, \sigma^{2}\right)$.

Regresi nonparametrik spline dapat dituliskan sebagai berikut (Eubank, 1999):

$$
y=\sum_{j=0}^{p-1} \beta_{j} x_{i}^{j}+\sum_{l=1}^{r} \beta_{(p+l)}\left(x_{i}-k_{l}\right)_{+}^{p} .
$$

Estimasi regresi nonparametrik spline diperoleh dengan menggunakan metode maximum likelihood estimation (MLE). Persamaan (2) respons $Y_{i}$ diasumsikan berdistribusi normal dengan nilai tengah $f\left(t_{i}\right)$ dan variansi $\sigma^{2}$, sehingga fungsi densitas peluang $Y_{i}$ dengan $f(t)>0, \sigma^{2}>0$. Estimasi parameter spline dapat dituliskan sebagai berikut :

$$
\widehat{Y}=x\left(x^{\prime} x\right)^{-1} x^{\prime} Y .
$$

Terdapat beberapa metode yang digunakan untuk memilih titik knot optimal, salah satunya yaitu dengan metode GCV .Titik knot optimal dipilih berdasarkan nilai GCV. GCV dapat dirumuskan sebagai berikut (Eubank, 1999):

$$
\operatorname{GCV}(K)=\frac{\operatorname{MSE}(K)}{\left(n^{-1} \operatorname{tr}[I-A(K)]\right)^{2}}
$$

dengan

$$
\operatorname{MSE}(K)=n^{-1} \sum_{i=1}^{n}\left(Y_{i}-\hat{f}\left(x_{i}\right)\right)^{2} .
$$

Salah satu kriteria yang digunakan untuk menentukan model terbaik yaitu koefisien determinasi $\left(R^{2}\right)$ dirumuskan sebagai berikut :

$$
R^{2}=\frac{\sum_{i}^{n}\left(\widehat{y}_{l}-\bar{y}\right)^{2}}{\sum_{i}^{n}\left(y_{i}-\bar{y}\right)^{2}}
$$

\section{METODE PENELITIAN}

\subsection{Jenis dan Sumber Data}

Data yang digunakan dalam penelitian ini berupa data sekunder yang diperoleh melalui website Badan Pusat Statistik. Data tersebut yaitu data rata-rata lama sekolah masingmasing provinsi di Indonesia tahun 2019 dengan banyaknya observasi yaitu 34 provinsi.

\subsection{Variabel Penelitian}

Terdapat dua jenis variabel yang digunakan dalam penelitian ini yaitu variabel respon $(Y)$ dan variabel prediktor $(X)$. Variabel respon dalam penelitian ini yaitu rata-rata lama sekolah masing-masing provinsi di Indonesia tahun $2019(Y)$. Penelitian ini menggunakan enam variabel prediktor yaitu persentase penduduk miskin $\left(X_{1}\right)$, proporsi disabilitas anak $\left(X_{2}\right)$, angka melek huruf $\left(X_{3}\right)$, angka putus sekolah jenjang SD $\left(X_{4}\right)$, angka putus sekolah jenjang SMP $\left(X_{5}\right)$ dan angka putus sekolah jenjang SMA $\left(X_{6}\right)$.

\subsection{Metode Analisis Data}

Analisis dalam penelitian ini menggunakan metode analisis regresi nonparametrik spline multivariable. Langkah-langkah yang 
dilakukan dalam penelitian ini adalah sebagai berikut :

1. Menyajikan statistika deskriptif dari setiap variabel.

2. Memilih titik knot optimal berdasarkan GCV yang paling minimum.

3. Memodelkan rata-rata lama sekolah dengan variabel-variabel prediktornya menggunakan regresi nonparametrik spline dengan titik knot optimal yang diperoleh dari langkah nomor 2.

4. Menghitung nilai koefisien determinasi $\left(R^{2}\right)$ dari model.

5. Membuat interpretasi dari model yang diperoleh dan membuat kesimpulan yang diperoleh berdasarkan model.

\section{PEMBAHASAN}

\subsection{Deskripsi Data}

Karakteristik dari masing-masing variabel disajikan dalam statistika deskriptif sebagai berikut.

Tabel 1. Statistika Deskriptif Variabel Penelitian

\begin{tabular}{|c|c|c|c|c|}
\hline Variabel & Mean & $\begin{array}{c}\text { St. } \\
\text { Deviasi }\end{array}$ & Min & Max \\
\hline$Y$ & 8,962 & 0,841 & 6,85 & 11,11 \\
\hline$X_{1}$ & 10,427 & 5,437 & 3,78 & 26,64 \\
\hline$X_{2}$ & 3,459 & 1,321 & 1,40 & 7,00 \\
\hline$X_{3}$ & 96,340 & 4,295 & $7, .00$ & 99,80 \\
\hline$X_{4}$ & 0,370 & 0,369 & 0,00 & 2,00 \\
\hline$X_{5}$ & 1,070 & 0,707 & 0,18 & 2,91 \\
\hline$X_{6}$ & 1,760 & 1,562 & 0,18 & 6,10 \\
\hline
\end{tabular}

Rata-rata lama sekolah ( $Y$ ) tahun 2019 tercatat sebesar 8,75 tahun. Angka tesebut telah mengalami peningkatan sebesar $0,17 \%$ dibandingkan tahun sebelumnya namun masih belum dapat memenuhi target yang ditetapkan pemerintah yaitu 9 tahun. DKI Jakarta menempati posisi teratas dengan $Y$ lebih dari 11 tahun yang artinya rata-rata penduduk DKI Jakarta sudah bisa mengenyam pendidikan sampai SMA kelas XII. Di sisi lain, penduduk 15 tahun ke atas di Papua rata-rata bersekolah hanya sampai kelas $6 \mathrm{SD} /$ sederajat yang artinya rata-rata penduduk Papua hanya mampu mengenyam pendidikan sampai bangku SD.
Variabel $X_{1}$ merupakan persentase penduduk miskin. Rata-rata $X_{1}$ yaitu sebesar $10,427 \%$ menurun $0,44 \%$ dibandingkan tahun 2018. $X_{1}$ terbesar yaitu Provinsi Papua sedangkan terendah yaitu Provinsi Bali. Nilai standar deviasi sebesar 5,437 menunjukkan bahwa data cukup beragam. Variabel $X_{2}$ merupakan proporsi disabilitas anak. Rata-rata $X_{2}$ adalah sebesar 3,459\% dengan status tidak bersekolah yang lebih besar dibandingkan yang bersekolah. $X_{2}$ terbesar yaitu $7 \%$ pada Provinsi Sulawesi Tengah sedangkan terendah yaitu $1,4 \%$ pada Provinsi Jambi. Variabel $X_{3}$ merupakan angka melek huruf. Rata-rata $X_{3}$ adalah sebesar 96,34\% meningkat sebesar 0,24 persen dibandingkan tahun sebelumnya. $X_{3}$ terbesar yaitu Sulawesi Utara sedangkan terendah yaitu Papua. Nilai standar deviasi cukup besar yaitu 4,295 menunjukkan data cukup beragam. Variabel $X_{4}$ merupakan angka putus sekolah jenjang SD. Rata-rata $X_{4}$ adalah sebesar 0,37. Angka tersebut sudah mampu melampaui target pemerintah yaitu $1 \% . X_{4}$ terbesar yaitu Papua sedangkan terendah yaitu Kalimantan Utara. Variabel $X_{5}$ merupakan angka putus sekolah jenjang SMP. Rata-rata $X_{5}$ adalah sebesar $1,07 \%$. Angka tersebut belum mampu mencapai target yang ditetapkan pemerintah yaitu $1 \% . X_{5}$ terbesar yaitu Sulawesi Barat sedangkan terendah yaitu Papua Barat. Variabel $X_{6}$ merupakan angka putus sekolah jenjang SMA. Rata-rata $X_{6}$ adalah sebesar $1,76 X_{6}$. Angka tersebut belum mampu mencapai target yang ditetapkan pemerintah yaitu $1 \%$. $X_{6}$ terbesar yaitu DKI Jakarta sedangkan yaitu $X_{6}$ terendah yaitu Nusa Tenggara Barat.

\subsection{Pemilihan Titik Knot}

Pemilihan titik knot dalam penelitian ini dilakukan menggunakan metode GCV. Titik knot optimal dipilih berdasarkan nilai GCV yang paling minimum. Pada penelitian ini pemilihan titik knot dibatasi dari satu titik knot, dua titik knot, tiga titik knot, dan empat titik knot dengan spline linear (orde 2) dan spline kuadratik (orde 3). Hal ini bertujuan untuk mempermudah interpretasi dan menghindari terbentuknya matriks yang singular. Analisis data dilakukan menggunakan software $\mathrm{R}$.

Pada Tabel 2. berikut ini disajikan nilai GCV masing-masing titik knot beserta orde knot. 
Tabel 2. Nilai GCV dari Variasi Titik Knot dan Orde

\begin{tabular}{|c|c|c|}
\hline Orde & $\begin{array}{c}\text { Banyak Titik } \\
\text { Knot }\end{array}$ & GCV \\
\hline \multirow{4}{*}{ Orde 2 } & 1 Titik Knot & 0,20 \\
\cline { 2 - 3 } & 2 Titik Knot & 0,16 \\
\cline { 2 - 3 } & 3 Titik Knot & 0,22 \\
\cline { 2 - 3 } & 4 Titik Knot & $\mathbf{0 , 0 7}$ \\
\hline \multirow{4}{*}{ Orde 3 } & 1 Titik Knot & 0,36 \\
\cline { 2 - 3 } & 2 Titik Knot & 0,36 \\
\cline { 2 - 3 } & 3 Titik Knot & 0,68 \\
\cline { 2 - 3 } & 4 Titik Knot & 20924,52 \\
\hline
\end{tabular}

Berdasarkan Tabel 2 dapat diketahui bahwa nilai GCV minimum yaitu 0.07 pada orde 2 dengan empat titik knot. Adapaun titik knot optimal yang diperoleh yaitu 6,$1 ; 7,88 ; 12,34$; 14,$99 ; 2,5 ; 3,1 ; 3,8 ; 4,8 ; 93,54 ; 97,72 ; 98,75$; 99,$03 ; 0,18 ; 0,32 ; 0,6 ; 0,65 ; 0,32 ; 0,84 ; 1,17$; dan 1,71 . Oleh karena itu, diputuskan bahwa model terbaik yang akan dipilih adalah model spline linier (orde 2) dengan 4 titik knot.

\subsection{Estimasi Parameter Model Spline}

Estimasi model regresi nonparametrik spline orde 2 dengan empat titik knot dapat dituliskan sebagai berikut.

$$
\begin{aligned}
\hat{Y}= & \hat{\beta}_{0}+\hat{\beta}_{1} X_{1}+\hat{\beta}_{2}\left(X_{1}-K_{1}\right)_{+}^{1} \\
& +\hat{\beta}_{3}\left(X_{1}-K_{2}\right)_{+}^{1}+\hat{\beta}_{4}\left(X_{1}-K_{3}\right)_{+}^{1} \\
& +\hat{\beta}_{5}\left(X_{1}-K_{4}\right)_{+}^{1}+\hat{\beta}_{6} X_{2} \\
& +\hat{\beta}_{7}\left(X_{2}-K_{5}\right)_{+}^{1}+\hat{\beta}_{8}\left(X_{2}-K_{6}\right)_{+}^{1} \\
& +\hat{\beta}_{9}\left(X_{2}-K_{7}\right)_{+}^{1}+\hat{\beta}_{10}\left(X_{2}-K_{8}\right)_{+}^{1} \\
& +\hat{\beta}_{11} X_{3}+\hat{\beta}_{12}\left(X_{3}-K_{9}\right)_{+}^{1} \\
& +\hat{\beta}_{13}\left(X_{3}-K_{10}\right)_{+}^{1}+\hat{\beta}_{14}\left(X_{3}-K_{11}\right)_{+}^{1} \\
& +\hat{\beta}_{15}\left(X_{3}-K_{12}\right)_{+}^{1}+\hat{\beta}_{16} X_{4} \\
& +\hat{\beta}_{17}\left(X_{4}-K_{13}\right)_{+}^{1}+\hat{\beta}_{18}\left(X_{4}-K_{14}\right)_{+}^{1} \\
& +\hat{\beta}_{19}\left(X_{4}-K_{15}\right)_{+}^{1}+\hat{\beta}_{20}\left(X_{4}-K_{16}\right)_{+}^{1} \\
& +\hat{\beta}_{21} X_{5}+\hat{\beta}_{22}\left(X_{5}-K_{17}\right)_{+}^{1} \\
& +\hat{\beta}_{23}\left(X_{5}-K_{18}\right)_{+}^{1}+\hat{\beta}_{24}\left(X_{5}-K_{19}\right)_{+}^{1} \\
& +\hat{\beta}_{25}\left(X_{5}-K_{20}\right)_{+}^{1}+\hat{\beta}_{26} X_{6} \\
& +\hat{\beta}_{27}\left(X_{6}-K_{21}\right)_{+}^{1}+\hat{\beta}_{28}\left(X_{6}-K_{22}\right)_{+}^{1} \\
& +\hat{\beta}_{29}\left(X_{6}-K_{23}\right)_{+}^{1}+\hat{\beta}_{30}\left(X_{6}-K_{24}\right)_{+}^{1}
\end{aligned}
$$

dengan $\hat{Y}$ adalah rata-rata lama sekolah masingmasing provinsi di Indonesia tahun 2019, $X_{1}$ adalah persentase penduduk miskin, $X_{2}$ adalah proporsi disabilitas anak, $X_{3}$ adalah angka melek huruf, $X_{4}$ adalah angka putus sekolah jenjang SD, $X_{5}$ adalah angka putus sekolah jenjang SMP dan $X_{6}$ adalah angka putus sekolah jenjang SMA.

Estimasi parameter spline diperoleh menggunakan software $\mathrm{R}$ dan disajikan dalam Tabel 3. Parameter yang digunakan dilambangkan dengan beta $(\beta)$ dan diperoleh sebanyak 31 .

Estimasi parameter beserta titik knot optimal yang telah diperoleh kemudian disubstitusikan dalam persamaan 8. Adapun estimasi model spline yang diperoleh dapat dilihat pada persamaan (9).

Tabel 3. Estimasi Parameter Model

\begin{tabular}{|c|l|c|l|}
\hline Parameter & $\begin{array}{c}\text { Nilai } \\
\text { Estimasi }\end{array}$ & Parameter & $\begin{array}{c}\text { Nilai } \\
\text { Estimasi }\end{array}$ \\
\hline$\hat{\beta}_{0}$ & 13,36 & $\hat{\beta}_{16}$ & $-1,89$ \\
\hline$\hat{\beta}_{1}$ & $-0,20$ & $\hat{\beta}_{17}$ & $-1,80$ \\
\hline$\hat{\beta}_{2}$ & 0,19 & $\hat{\beta}_{18}$ & 4,72 \\
\hline$\hat{\beta}_{3}$ & $-0,02$ & $\hat{\beta}_{19}$ & 6,19 \\
\hline$\hat{\beta}_{4}$ & $-0,10$ & $\hat{\beta}_{20}$ & $-9,34$ \\
\hline$\hat{\beta}_{5}$ & 0,18 & $\hat{\beta}_{21}$ & 0,93 \\
\hline$\hat{\beta}_{6}$ & $-0,32$ & $\hat{\beta}_{22}$ & $-3,89$ \\
\hline$\hat{\beta}_{7}$ & 2,81 & $\hat{\beta}_{23}$ & 4,08 \\
\hline$\hat{\beta}_{8}$ & $-5,67$ & $\hat{\beta}_{24}$ & $-0,66$ \\
\hline$\hat{\beta}_{9}$ & 5,1 & $\hat{\beta}_{25}$ & $-0,75$ \\
\hline$\hat{\beta}_{10}$ & $-2,23$ & $\hat{\beta}_{26}$ & 2,24 \\
\hline$\hat{\beta}_{11}$ & $-0,04$ & $\hat{\beta}_{27}$ & $-2,66$ \\
\hline$\hat{\beta}_{12}$ & 0,23 & $\hat{\beta}_{28}$ & $-1,71$ \\
\hline$\hat{\beta}_{13}$ & $-0,14$ & $\hat{\beta}_{29}$ & $-1,34$ \\
\hline$\hat{\beta}_{14}$ & 0,72 & $\hat{\beta}_{30}$ & $-0,22$ \\
\hline$\hat{\beta}_{15}$ & $-1,27$ & & \\
\hline
\end{tabular}

$$
\begin{aligned}
\hat{Y}= & 13,36-0,20 x_{1}+0,19\left(x_{1}-6,1\right)_{+}^{1} \\
& -0,02\left(x_{1}-7,88\right)_{+}^{1}-0,10\left(x_{1}-12,34\right)_{+}^{1} \\
& +0,18\left(x_{1}-14,99\right)_{+}^{1} \\
& -0,32 x_{2}+2,81\left(x_{2}-2,5\right)_{+}^{1} \\
& -5,67\left(x_{2}-3,1\right)_{+}^{1}+5,1\left(x_{2}-3,8\right)_{+}^{1} \\
& -2,23\left(x_{2}-4,8\right)_{+}^{1}-0,04 x_{3} \\
& +0,23\left(x_{3}-93,54\right)_{+}^{1} \\
& -0,14\left(x_{3}-97,72\right)_{+}^{1} \\
& +0,72\left(x_{3}-98,75\right)_{+}^{1} \\
& -1,27\left(x_{3}-99,03\right)_{+}^{1} \\
& -1,89 x_{4}-1,80\left(x_{4}-0,18\right)_{+}^{1} \\
& +4,72\left(x_{4}-0,32\right)_{+}^{1}+6,19\left(x_{4}-0,6\right)_{+}^{1} \\
& -3,89\left(x_{4}-0,65\right)_{+}^{1}+0,93 x_{5} \\
& -0,66\left(x_{5}-1,17\right)_{+}^{1}+4,08\left(x_{5}-0,84\right)_{+}^{1}-0,75\left(x_{5}-1,71\right)_{+}^{1} \\
& +2,24 x_{6}-2,66\left(x_{6}-0,56\right)_{+}^{1} \\
& +1,71\left(x_{6}-1,43\right)_{+}^{1}-1,34\left(x_{6}-2,06\right)_{+}^{1} \\
& -0,22\left(x_{6}-3,84\right)_{+}^{1}
\end{aligned}
$$

Berdasarkan model tersebut diperoleh nilai koefisien determinasi sebesar 0,9991016. Hal tersebut menunjukkan bahwa model yang diperoleh mampu menjelaskan keragaman nilai RLS masing-masing provinsi di Indonesia menggunakan regresi nonparametrik spline dengan variabel persentase penduduk miskin, proporsi disabilitas anak, angka melek huruf, angka putus sekolah jenjang SD, angka putus 
sekolah jenjang SMP dan angka putus sekolah jenjang SMA sebesar 99,91016\% dan sisanya sebesar 0,0008984\% dijelaskan oleh variabel lain diluar model ataupun galat.

\subsection{Interpretasi Model Spline}

Interpretsi dari model regresi nonparametrik spline linear dengan empat titik knot dapat dijabarkan sebagai berikut :

1. Apabila $X_{2}, X_{3}, X_{4}, X_{5}$ dan $X_{6}$ konstan maka pengaruh persentase kemiskinan $\left(X_{1}\right)$ terhadap RLS $(Y)$ yaitu

$$
\begin{aligned}
\hat{Y}= & 13,36-0,20 X_{1} \\
& +0,19\left(X_{1}-6,1\right)_{+}^{1} \\
& -0,02\left(X_{1}-7,88\right)_{+}^{1} \\
& -0,10\left(X_{1}-12,34\right)_{+}^{1} \\
& +0,18\left(X_{1}-14,99\right)_{+}^{1}
\end{aligned}
$$

$$
\hat{Y}=\left\{\begin{array}{cl}
13,36-0,20 X_{1} & ; X_{1}<6,1 \\
12,201-0,01 X_{1} & ; 6,1 \leq X_{1}<7,88 \\
12,3586-0,03 X_{1} & ; 7,88 \leq X_{1}<12,34 \\
13,5926-0,13 X_{1} & ; 12,34 \leq X_{1}<14,99 \\
10,8944+0,05 X_{1} & ; X_{1} \geq 14,99
\end{array}\right.
$$

Apabila persentase kemiskinan $\left(X_{1}\right)$ suatu provinsi berada di bawah angka $6,1 \%$ maka peningkatan persentase kemiskinan $\left(X_{1}\right)$ sebesar satu persen akan mengakibatkan penurunan RLS $(Y)$ sebesar 0,20 tahun. Apabila persentase kemiskinan $\left(X_{1}\right)$ suatu provinsi berada pada interval $6,1 \%$ sampai $7,88 \%$ maka peningkatan persentase kemiskinan $\left(X_{1}\right)$ sebesar satu persen akan mengakibatkan penurunan RLS $(Y)$ sebesar 0,01 tahun. Apabila persentase kemiskinan $\left(X_{1}\right)$ suatu provinsi berada pada interval $7.88 \%$ sampai $12,34 \%$ maka peningkatan persentase kemiskinan $\left(X_{1}\right)$ sebesar satu persen akan mengakibatkan penurunan RLS $(Y)$ sebesar 0,03 tahun. Apabila persentase kemiskinan $\left(X_{1}\right)$ suatu provinsi berada pada interval $12,34 \%$ sampai $14,99 \%$ maka peningkatan persentase kemiskinan $\left(X_{1}\right)$ sebesar satu persen akan mengakibatkan penurunan RLS $(Y)$ sebesar 0,13 tahun. Apabila persentase kemiskinan $\left(X_{1}\right)$ suatu provinsi berada di atas angka $14,99 \%$ maka peningkatan persentase kemiskinan $\left(X_{1}\right)$ sebesar satu persen akan mengakibatkan peningkatan RLS $(Y)$ sebesar 0,05 tahun.

2. Apabila $X_{1}, X_{3}, X_{4}, X_{5}$ dan $X_{6}$ konstan maka pengaruh proporsi disabilitas anak $\left(X_{2}\right)$ terhadap RLS $(Y)$ yiatu

$$
\begin{gathered}
\hat{Y}=13.36-0,32 X_{2} \\
+2,81\left(X_{2}-2,5\right)_{+}^{1}
\end{gathered}
$$

$$
\begin{gathered}
\quad-5,67\left(X_{2}-3,1\right)_{+}^{1} \\
+5,1\left(X_{2}-3,8\right)_{+}^{1} \\
\quad-2.23\left(X_{2}-4,8\right)_{+}^{1} \\
\hat{Y}=\left\{\begin{array}{cl}
13,36-0,32 X_{2} & ; X_{2}<2,5 \\
6,335+2,49 X_{2} & ; 2,5 \leq X_{2}<3,1 \\
23,912-3,18 X_{2} & ; 3,1 \leq X_{2}<3,8 \\
4,532+1,92 X_{2} & ; 3,8 \leq X_{2}<4,8 \\
15,236-0,31 X_{2} & ; X_{2} \geq 4,8
\end{array}\right.
\end{gathered}
$$

Apabila proporsi disabilitas anak $\left(X_{2}\right)$ suatu provinsi berada di bawah angka $2,5 \%$ maka peningkatan proporsi disabilitas anak $\left(X_{2}\right)$ sebesar satu persen akan mengakibatkan penurunan RLS $(Y)$ sebesar 0,32 tahun. Apabila proporsi disabilitas anak $\left(X_{2}\right)$ suatu provinsi berada pada interval 2,5\% sampai $3,1 \%$ maka peningkatan proporsi disabilitas anak $\left(X_{2}\right)$ sebesar satu persen akan mengakibatkan peningkatan RLS $(Y)$ sebesar 2,49 tahun. Apabila proporsi disabilitas anak $\left(X_{2}\right)$ suatu provinsi berada pada interval $3,1 \%$ sampai $3,8 \%$ maka peningkatan proporsi disabilitas anak $\left(X_{2}\right)$ sebesar satu persen akan mengakibatkan penurunan RLS $(Y)$ sebesar 3,18 tahun. Apabila proporsi disabilitas anak $\left(X_{2}\right)$ suatu provinsi berada pada interval $3,8 \%$ sampai $4,8 \%$ maka peningkatan proporsi disabilitas anak $\left(X_{2}\right)$ sebesar satu persen akan mengakibatkan peningkatan RLS $(Y)$ sebesar 1,92 tahun. Apabila proporsi disabilitas anak $\left(X_{2}\right)$ suatu provinsi berada di atas angka 4,8\% maka peningkatan proporsi disabilitas anak $\left(X_{2}\right)$ sebesar satu persen akan mengakibatkan penurunan RLS $(Y)$ sebesar 0,31 tahun.

Begitu pula untuk hubungan $X_{3}, X_{4}, X_{5}, X_{6}$ terhadap rata-rata lama sekolah $(Y)$.

\section{SIMPULAN DAN SARAN}

\subsection{Simpulan}

Model regresi terbaik yang diperoleh dalam pemodelan RLS di Indonesia dengan variabel persentase penduduk miskin, proporsi disabilitas anak, angka melek huruf, angka putus sekolah jenjang SD, angka putus sekolah jenjang SMP dan angka putus sekolah jenjang SMA yaitu menggunakan orde linear (orde 2) dengan empat titik knot. Nilai koefisien determinasi yang diperoleh sebesar 0,999 dengan nilai GCV yaitu 0,079 . 


\subsection{Saran}

Saran yang dapat penulis berikan untuk penelitian selanjutnya yaitu sebaiknya dapat menyederhanakan model yang diperoleh agar sesuai dengan principle of parsimony model atau prinsip kesederhanaan model tanpa mengurangi nilai koefisien determinasi yang diperoleh.

\section{DAFTAR PUSTAKA}

Astiti, D. A. W., Sumarjaya, I., \& Susilawati, M. (2016). Analisis Regresi Nonparametrik Spline Multivariat untuk Pemodelan Indikator Kemiskinan di Indonesia. EJurnal Matematika, 5(3), 111-116.

BPS. (2020). Potret Pendidikan Indonesia 2019. Statistik Pendidikan.

Eubank, R. (1999). Nonparametric Regressionand Spline Smoothing Second edition. New York: Marcel Dekker.

Griggs, W. (2013). Penalized Spline Regression and Its Applications. Washington D.C.: Whitman College.

Kurtner, M., \& Nachtsheim, C. (2004). Applied Linear Statistical Models. New York: The McGraw-Hill Companies.

Prahutama, A., Utama, T., Caraka, R., \& Zumrohtuliyosi, D. (2014). Pemodelan Inflasi Berdasarkan Harga-Harga Pangan Menggunakan Spline Multivariabel. Media Statistika. 7(2), 89-94. 